University of Warwick institutional repository: http://go.warwick.ac.uk/wrap

This paper is made available online in accordance with publisher policies.

Please scroll down to view the document itself. Please refer to the repository record for this item and our policy information available from the repository home page for further information.

To see the final version of this paper please visit the publisher's website. Access to the published version may require a subscription.

Author(s): Hughes, Christina

Article Title: The pleasures of learning at work: Foucault and phenomenology compared Year of publication: 2007

Link to published version: http://dx.doi.org/10.1080/01425690701253430 
The Pleasures of Learning at Work: Foucault and Phenomenology Compared

\author{
Christina Hughes \\ Department of Sociology \\ University of Warwick \\ Coventry CV4 7AL \\ C.L.Hughes@warwick.ac.uk
}

Word Length: 7013

British Journal of Sociology of Education (2007) 
Biographical Details: Christina Hughes is a Professor in the Department of Sociology, University of Warwick. Her current research interests are focused on the development of feminist theory, particularly in respect of conceptual understandings and in exploring aspects of dissemination in the social sciences. Her recent publications include (2002) Women's Contemporary Lives: Within and Beyond the Mirror, London, Routledge; (2002) Key Concepts in Feminist Theory and Research, London Sage and (2003) (Ed) Disseminating Qualitative Research in Educational Settings, Maidenhead, Open University Press 


\title{
The Pleasures of Learning at Work: Foucault and Phenomenology Compared
}

\begin{abstract}
This paper provides a comparative account of two conceptualisations of pleasure. The first draws on Foucault's analysis of bio-power. The second provides a phenomenological account where pleasure is viewed as an aspect of our immediate consciousness. These conceptualizations are illuminated through an analysis of employees' accounts of learning at work. Overall, the paper demonstrates how, in a Foucauldian analysis, pleasure disappears as it becomes a cipher for power whereas within the phenomenological account pleasure is foregrounded but power disappears. The concluding section focuses on the problems of both conceptualizations and explores whether we should simply accept that different analytical frameworks do different work for us or whether we should be more concerned at the losses, and gains, associated with theoretical choices. The conclusion further asks whether a concern to foreground pleasure in accounts of learning represents an antidote to the pessimism of much critical analysis or whether we should treat pleasure as a morally duplicitous category that encourages political apathy.
\end{abstract}




\section{The Pleasures of Learning at Work: Foucault and Phenomenology Compared}

\section{Introduction}

Over a decade ago, McWilliam (1996) commented on the paucity of attention paid to analytically recognising the significance of pleasure in learning. She noted how concepts of pleasure had informed cultural theory and that there was potential for much fruitful borrowing to develop an analysis of the erotics of pedagogy. Certainly, pleasure has had a significant impact in cultural studies. Nonetheless, when it comes to analyses of learning, it would appear that, by and large, McWilliam's intervention has fallen on deaf ears (see, however, Edwards and Usher, 2000; Edwards and Usher; 2001; Gard and Meyenn, 2000; Hughes, 2002; Swan, 2005).

Notwithstanding this limited attention to pleasure and learning, analyses to date indicate a variety of ways in which pleasure has been conceptualized. For example, McWilliam's (1996, see also McWilliam and Jones, 1996; McWilliam 1999) analysis draws attention to how eroticism, sexuality and seduction not only induce a desire for learning but are part of the pedagogic arsenal of the teacher. Drawing on McWilliam, Edwards and Usher's (2000; 2001) discussion of embodied pedagogies recognises the dualistic distinctions between desire and motivation. For example, Edwards and Usher illustrate how the former views the learner as an active lived body whilst the latter constitutes the learner as an active enquiring mind. Embodied pedagogy attempts to draw these binaries together.

These accounts foreground the body in their focus on the pedagogical pleasures associated with the realm of erotics and sexuality. They also foreground the teacher as pedagogue. My own earlier work on nomadic moments of pleasure (Hughes, 2002) is more concerned with the learner's experience of pleasure. Here, I have noted how certain forms of pleasure can give rise to a sense of incorporeality as 'material existence is fleetingly suspended' ( $p$ 418). My account of nomadic moments sought to highlight, what I now understand from Barthes (1975), a sense of 
disruptive rapture experienced when catching a glimpse of previously unknown/unknowable vistas. In his discussion of the pleasures and bliss of the text, Barthes delineated between textual plaisir and textual jouissance. Textual plaisir provides easy going enjoyment but does not disrupt cultural codes. Textual jouissance represents the disruptive rapture experienced when texts enable us to transgress or see beyond cultural limits (Groden and Kreiswirth, 1997). Nomadic moments are closer to textual jouissance than textual plaisir.

This paper seeks to further explore the potential, and limits, of pleasure for developing understandings of learning. I retain the focus on the learner and apply this to data derived from research conducted into employer-sponsored, work-linked learning. However, my primary concerns do not lie with illuminating a specific field of learning. Rather, they are more concerned with the adequacy of knowledge produced through alternative analytic frames. This paper is, therefore, organized through a comparative approach. The first is a Foucauldian analysis. Foucault (1985) has explored pleasure as an aspect of bio-power and central to the development of the ethical subject. The aim is to illustrate how the pleasures derived from becoming an ethical subject illuminate the operations of power. I illustrate the forms through which such transformation works by taking two concepts from Foucault's analysis of sexual pleasures in classical Greek society. These are quantification and role.

Clearly Foucault stands amongst the major theorists of pleasure and is, of course, widely drawn upon within educational literatures. However, Foucauldian theorists tend to emphasise power at the expense of pleasure. In consequence, there is a danger that pleasure becomes a cipher for power and the immediacy of pleasurable - even nomadic - moments become formed into more portentous concerns about their illusionary nature in the processes of subjugation. Thus, rather than focusing on aspects of joy in pleasure, Foucauldian analyses can leave us with the feeling that pleasure has to be understood in more sinister, malevolent ways as it becomes part of the arsenal that colonises the subject. It is for these reasons that the second analysis provided here is a phenomenological account where the concern is to privilege pleasure as a lived moment. This is, in the way of phenomenology, a descriptive account and here the aim is to understand 
and respect the varied sources and meanings of pleasure for those engaged in learning at work. Here, I focus on three aspects associated with the production of pleasures. These are time, learning environment and the unexpected of achievement.

The concluding section explores the problems of both forms of analysis. In this respect, the question is raised as to whether we should consider alternative analytic framings as simply doing different work for us in the production of knowledge or whether they can be viewed as complementary. A further concern raised is the use of pleasure as a conceptual tool in developing critical accounts of learning. Can, for example, the joy of pleasure serve as an antidote to what Swan (2005) describes as the reductive fatalism of critical analyses or is pleasure a morally duplicitous category that encourages political apathy?

\section{Methodology}

My methodological approach has been informed by recent interest in the continuing salience and potentiality of archived data (Parry and Mauthner, 2004). Whilst this is commonly understood in terms of access to data collected by others, in this case the data draws directly from research with which I have personally been involved. This is a Leverhulme funded study entitled Work, Education and Adult Life (1993-6) that was undertaken with colleagues Loraine Blaxter and Malcolm Tight. This study explored the learning careers of employees in six organisations. These were two private organisations, two public organisations and two from the voluntary sector (Blaxter, Hughes and Tight, 1997). In all, one hundred and twenty employees were interviewed. This included those responsible for the delivery of staff development policies and practices together with employees in a range of job roles and at different levels of the organization. Each interview focused on the interviewee's lifetime experience of education, training and learning and how they related these to their work and other aspects of their lives. 
The data provided here is taken from the twenty employees interviewed in one of the private organisations referred to as Car Co. This was a manufacturing plant that aimed to be a world class learning organisation. There was, in consequence, extensive provision for learning and development through employee development schemes together with attempts to change the culture of the company to one where learning was viewed as central. All employees had a personal development record which linked their individual learning needs with corporate and team objectives.

In returning to these data sets, the aim is not to produce a generalisable account but rather to illustrate one of the ways in which researchers can retrieve data previously left on the cutting room floor. Given the nature of the theoretical frames for each of the following two sections, different data has been selected to illuminate key points. Indeed, to heighten the descriptive potential of the phenomenological account, no personal or contextual details are provided in respect of the data in that part of the paper.

\section{Pleasure in the Production of an Admirable Life}

Foucault (1985) analysed pleasure in terms of the historical production of the ethical subject and, in his later works on the history of sexuality, he explored pleasure as a particular relationship to the self. Through this work Foucault demonstrates how pleasure in sex is founded in selfdiscipline and regulation rather than in permissive or excessive conduct. In addition, Foucault demonstrates the inter-relationship between power, self-domination and pleasure in the production of an admirable life by commenting that 'In the domain of pleasures, virtue was not 
conceived as a state of integrity, but as a relationship of domination, a relation of mastery' (Foucault, 1985: 70).

Davies et al (2001) demonstrate one of the ways in which we might understand this interrelationship in their analysis of the production of the 'good' pupil at school. In particular, they note how processes of appropriation depend not only on knowing what the teacher wants and being able to produce it but also, and significantly, to want these things for one self. This desire for the 'goodies' of learning would certainly be evident in the production of the worthy employee who is taken up by, and is taking up, the discourses and practices of human resource development. However, the character of human resource development practices and discourses is quite 'unashamedly linked to market economics' (Garrick, 1998: 152). This lack of moral equivocation over the economic is sufficient to mark out a distinction between work based learning and schooling. Whereas there remains, at least, some contestation that the purpose of schooling is not simply to meet the economic needs of industry and the nation, the ultimate purpose of employee development programmes is absolutely about ensuring that the productive capabilities of employees are enhanced and developed. In this respect, the 'good' work based learner is the employee who takes pleasure in how learning, training and development opportunities enhance their own productive worth and that of the organisation.

The data that is presented here is drawn from those employees who, in parallel to Davies et al (2001), took pleasure in, and were successful at, getting the goodies of learning. This was in terms of the degree to which they took up the opportunities of employee development programmes, apprenticeships and other forms of training and development offered to them. It was also in terms of developing a moral sense of self as an active member of the organization that rested on identification with the organisation's learning mission. Indeed, as Garrick (op cit) notes, an analysis of this process highlights how the individual is not simply taken up by corporate objectives. Rather, colonisation of this kind encourages a sense of agency and, I would add, realism. This means that individuals do not perceive themselves as totally subsumed by 
organisational needs and requirements, nor are they cultural dupes. Rather, individuals view themselves as acting within, albeit limited, choices.

These processes of subjectification are, of course, subject to moral regulation and Foucault (1985) delineates quantification and role as the two concepts that are central to this process. In respect of quantification, Foucault notes, for example, how excess of sexual activity 'indicates a lack of self-restraint with regard to pleasure' ( $p$ 45). Through analysing the gendered division of sexual acts in terms of ' the one who performs the activity and the one on whom it is performed' (p 47) Foucault also illustrates how one had to stay within one's appropriate social role and function. In consequence, the 'major variable that engaged moral valuation, in addition to the "quantity of activity" criterion, was the question of remaining in one's role or abandoning it' ( $p$ 47). Using the concept of aphrodisia to delineate 'The manner in which this kind of pleasure was enjoyed was considered by them to be an ethical problem' ( $p$ 36) Foucault therefore comments that 'For a man, excess and passivity were the two main forms of immorality in the practice of the aphrodisia' (p 47).

Employment-linked learning clearly operates within a different moral terrain to that of sexuality in classical Greece. However, issues of quantity and role remain significant. In terms of quantity, lifelong learning and learning organization models emphasise repeated and consistent engagement in learning projects. There is no doubt, therefore, that in contemporary climates participation, rather than abstinence, is essential. However, the pejorative term 'learning junkie' also indicates that an individual can be viewed, in Foucault's terms, as someone who is too passive with regard to pleasure by letting it take hold of them. Excess, therefore, can be as morally wanting as under-participation. The difficulty is getting the balance right. Would we, for example, judge John, quoted below, as rather lax in terms of his passivity in the face of those pleasures he is experiencing in learning. Or should we simply note how John's sense of pleasure in recounting the considerable number of courses he had undertaken since joining Car Co indicates how the cultural development of being a learner in an organization striving for the accolade of learning organization raises the bar in terms of quantity? 
We had all been put through TQI training, TQ, total quality training, which was four days for managers, four solid days. ... What else did I do? Actually there are loads of courses, it is hard to remember them all. I was put on dove nest which was a leadership training course, pretty basic leadership training up in the Lake District using outward bound and whatever. I did, I won an LB at Warwick. It was IMDS in them days. It changed by monopoly. I did that for the two years duration. What are some of the others I have done? I have been down to London, Roffy Park, which was assertiveness training which was a strange type of course. I believe one of the senior managers couldn't make it and rather than waste the space they sent somebody and I went. There was various in house things we did with consultants, purposeful management which was off site. ... We did another one which was similar but everybody went through it including team leaders and some of the associates went through which was something different which was stress related and I thinking another where we were using the left hand side of the brain. A bit of lateral thinking. They put a hell of a lot of people through that. What else have I done? I did leadership. It was at some institute or other they hold it every year at Oxford University at Balliol College. [John, Line Manager]

It is certainly the case that the economic imperative of employment-related learning would currently encourage excess rather than restraint. It is also the case that in such situations pleasure can easily slip into a sense of tyranny when demands are too strong. This is because, as Jessica's words convey, becoming an employee in an organization with a strong emphasis on learning is premised upon insecurity and fear. Accordingly, this may also be the point where sheer quantity of demand upon the individual negates the pleasures that might be experienced:

... business things are moving at such a fast pace at the moment I can't see the need, you can't afford to stop learning, if you do then you will fall behind and perhaps you could drop off ... or something [Jessica, Administrator]. 
Both John and Jessica's comments indicate the complex inter-relation of quantity and pleasure where too much agency in seeking out learning can lead to being judged of weak moral character and where too much demand upon the individual can be perceived as despotic. Similarly, in terms of role or function, learning discourses directed at those in employment emphasise the need for all to be actively engaged in learning. Yet, the linkage between quantity and role should not be underestimated. In this regard, the division between those who engage in learning and those who do not reflect not only key social divisions but also changes in employment roles and therefore a changing sense of opportunity and appropriateness. John's remarks below indicate the continuing separation between those in senior roles who take up learning opportunities and those at the lower echelons of the organisation who do not. However, whilst lack of participation may imply moral latitude in terms of taking responsibility for one's learning, John's comments indicate how changing job role, in itself, increases a pleasurable sense of motivation:

You usually find the people that are more motivated [to engage in learning opportunities] inside the company have got responsible jobs, jobs which keep you involved more. I have worked on track [car assembly roles], it is terrible to motivate yourself even to come to work and that was years ago. Now I find it quite easy. [John, Line Manager]

Whilst John's empathy and personal experience suggest that he is less inclined to make a judgement against those in lower level jobs who do not take up learning opportunities, his remarks do convey a strong sense of individualism. Phil's comments reinforce this cultural aspect of learning at Car Co and further point towards the potential development of a blame culture where those that do not participate in learning, for whatever reasons, are subject to moral regulation:

The philosophy being that it is not my job to develop somebody anyway. It is that individual's. I can give him [sic] the guidance and coaching and point him in the right direction but unless he wants it at the start then there is not a lot I can do. That is the bit 
we are trying to get over to people. It is up to you. Come and tell us what you want to do. [Phil, Line Manager]

Such a view downplays the structural features that, as Jacky indicates, mitigate both for and against such opportunities. For those who work, for example, on car assembly (ie the track) the demands of the manufacturing process inhibit the necessary freedoms to go on courses or participate in learning projects. However, using the language of 'pushing for things', Jacky's words do indicate a sense of mastery of the self as a learner as she seeks out further opportunities:

I have had to really push for it myself. But now I am a team leader it is easier to release me. Whereas when I was on the track you have obviously got to get somebody to replace me whereas as a team leader they can manage for a week [Jacky, Team Leader].

The foregoing has focused on the production of the admirable life in a learning organization through which pleasure is linked to being fully colonized as the subject who actively seeks out opportunities for learning. Such an account is strongly concerned with the relation between power and pleasure. Thus, the language of 'pushing for' has a double meaning. It indicates how one can be positioned in employment roles where pushing for opportunities reflects differential access. It also indicates a strong sense of agency and desire in accessing the 'goodies' of learning. I now turn to a phenomenological account to explore the lived meanings of pleasure.

\section{Pleasure as a Thing Itself}

Central to the development of phenomenology is the work of Husserl (1931) whose philosophy contained the injunction that we should go back to things themselves. These 'things themselves' are 'phenomena that present themselves immediately to us as conscious human beings' (Crotty, 1998: 78). The phenomenological task is to go to the immediate data given to us and to describe 
what is constant and essential (Velarde-Mayol, 2000). This description would require us to use the method of eidetic reduction which 'consists of producing variations in the individual object until we see what is invariable in it' (Velarde-Mayol, 2000: 45).

In setting out these requirements, Husserl added a further injunction. It is only possible to know 'things themselves' if we set aside the ontological status of the phenomenon and see the world as it is before we learnt to see it. Not to do so would mean that our judgement of the phenomenon would include our a priori 'decisions about such ontological status [and] obviously, unchecked a priori judgements concerning the ontological status of the phenomenon would embroil [us] in equally unwanted presuppositions' (Primozic, 2001: 14). Here, Husserl drew on the Greek term epoché meaning 'suspension of judgement, abstention' (Velarde-Mayol, 2000: 47) to argue that we needed to bracket out all assumptions and ontological commitments that arise from our cultural understandings and received views of the world.

Clearly, phenomenology of this kind aspires to be an objectivist science. Its criticality rests on uncovering what has, to date, been withheld from view (Crotty, 1998). Notwithstanding, phenomenology has been subject to various developments and critiques. In this respect, there are two issues I would draw attention to here. These are, first, the problems of epoché. Second, how phenomenological principles have been translated into a set of methodological craft knowledges.

One of the principal critical developments of Husserl's epoché has been raised by the existentialist phenomenologist, Merleau-Ponty (1962). Through his fleshy metaphysics, MerleauPonty critiqued Husserl's injunction to bracket out received ways of knowing as problematic in terms of the possibilities of the idealism to which it aspires and because it maintains the bodymind dualism of Cartesian thought in its attempt to transcend the body and privilege the mind. Rather than treating the body as epistemologically inferior to the mind, Merleau-Ponty argued for their inter-connectivity. A classic example would be that when touching someone you are also being touched. In terms of pleasure, this would be understood to be, at one and the same time, 
an embodied sensation and the thought that pleasure is being experienced. In recognising this duality, Merleau-Ponty argued that, rather than bracketing out sensation and experience, 'The world of our experience is all we have to situate consciousness. The world is not some theoretical construction but a situation in which we find ourselves' (Promizic, 2001: 47).

Phenomonelogical forms of qualitative research have taken up these ideas and have developed a set of craft knowledges. Willis (2001) describes these as related to: description; bracketing and naming essential themes. Description is a key aim of phenomenology. To do this requires the researcher to bracket out their assumptions and knowledges. However, given Merleau-Ponty's injunction of the perspectival nature of perception, in the everyday of qualitative research this is understood in terms of the requirement that one states one's intellectual preferences and positionality, making them known and attempting to reframe understandings outside of these (Groenewald, 2004). Finally, in terms of naming essential themes one has to keep a focus on the elements of experience rather than linking themes to a 'person's recurring feelings [or] being caught up in too much analysis' (Willis, 2001: 12).

I take up these elements of phenomenology in order to provide a focus on pleasure as a lived moment of experience. This requires the stripping away of some of the usual analytic details upon which I would commonly draw. In consequence, and using the spirit of epoché, I intend to bracket out what I would describe as the 'natural' attitudes (sic) learnt from my feminist social science enculturation. This primarily relates to the feminist assumption that gender is always the difference that makes a difference. In this respect, I am following Moi's (1999: 291, emphasis in original) reminder that although, in principle, gender is always a relevant factor to be taken into account in all social analysis, 'one cannot always assume that gender is the most relevant factor in play in a given social situation'. What I hope to illustrate is that there are some sources of pleasure that can transcend a gender binary. In addition, and to further emphasise the descriptive nature of the account, I have removed all names and other contextual details of the individuals whose words are presented here. 
There is one final reason to portray pleasure in this form. This is to give credence to research respondents' own experiences of pleasure. My field notes indicate, embryonically, how respondents conveyed their pleasures both in their bodily dispositions during interviews and in what they said. Describing pleasurable moments or experiences often simultaneously invoked more animated and excited gestures, through for example moving closer towards me during the interview or changing hand movements. Alternatively, for those who expressed surprise that learning for work could be fun, their bodies appear more quiet and contemplative. In most cases, accounting for pleasure was usually said with a smile. The accounts below reflect on pleasure as an aspect of time, learning environment and the unexpected of achievement.

\section{Pleasure and Time}

Future, past and present are the three aspects of time that are drawn upon here to indicate how timing is implicated in experiences of pleasure. In terms of the future, the promise of reward and future gratification, seen in terms of an employee's hopes, dreams and anticipated pleasures, strongly conditions learning and work experiences. This is due to the rising significance of lifelong and work based learning as the route to maintaining, or accessing, employability and career progression. Whilst stereotypically the linkage of learning to future reward might be understood in terms of increased wages and status, as the following quote indicates, these can be viewed as lesser goals when the target of learning is viewed as the passport to an enjoyable job:

What I want is a job that I can enjoy. So for me the target is getting into a role that I am going to enjoy working in than anything rather than at the level it is at.

Looking back on past experiences is also significant as the past is reconfigured. Less pleasurable aspects of an experience are diminished as one is left with an overarching aura of having had a good time: 
It is great. Really good fun. So you are in there with all the engineers and you all start at the same point but at the same time you are doing day release to start your business course which is the ONC. When you start it is hard. It was hard work. But looking back I mean it was a real good time.

Finally, in terms of pleasures of the present, it is that aspect of serendipity that is relevant in the following example. Here, being in the right place at the right time not only produces the pleasure derived from feeling lucky but also produces a further range of sources of pleasure that include learning new skills and finding this leads directly to a job associated with those skills:

It was about five years ago I found there was a need for PCs inside the industry so I bought myself one. And I enjoyed doing it. So basically I am very lucky. ... Sometimes I have been in the right place at the right time I suppose. It is as simple as that. It is just that I enjoy computers, perhaps it could have been that computers didn't take off ... I have just enjoyed computers. I am one of the lucky ones really. There are a lot of people dealing with computers who never had the opportunity that I have had.

\section{Pleasure and the Learning Environment}

Various classic texts on teaching adults (see for example Brookfield, 1986) indicate the importance of what Tight (1998) refers to as the chemistry of instruction. This is related to producing a pedagogical ethos that is respectful to learner's experiences and which produces a collaborative and proactive learning environment. This environment includes the physical conditions of, say, the classroom as well as the forms through which learners are encouraged to work together. Thus, teachers of adults will move desks and chairs around a room to get the atmosphere 'right'. They encourage small group interaction and view their key role as a facilitator of others' learning. This combination of space, place and form is viewed as central to empowerment and motivation in order that adults can fully become self-directed learners. 
Certainly, providing supportive spaces for learners to learn with and from each other is an important pedagogical goal that can leave the learner with a sense of the pleasure of having been with a 'good year group'. In this case, being of a similar age is also relevant:

Most of the people that started on the apprenticeship 16, 17 year olds and I started when I was 18. There were a few people that were 18,19 . Other people my own age there. I don't know. I had quite a good year group to be honest. We sort of gelled really well and supported each other quite a lot ... there would be always be somebody there to help you. At the same time you would help them with things that you perhaps, things that I could do that they couldn't or perhaps while they were helping you ...

Notwithstanding, finding oneself in a challenging environment that is perceived as a step-up from one's usual place can also produce the pleasure of reflecting that 'It is very good. A very good course. Fairly high powered.'

The literature on adult learning also places a considerable emphasis on the place of experience in learning. In consequence, providing learners with relevant experiential placements that link learning and work is also seen to enhance learning and motivation. From the learner's viewpoint, however, fun can be an apt description:

I had a fun placement. I worked in the driving experience which is marketing, commercial type, side. Actually being out there with the public. Going to the Royal Show and sort of getting the people in vehicles and taking them for a ride round and talking to the farmers and the people that would be interested in buying the vehicles and just chatting to the public. That was really good.

\section{Pleasure and a Sense of Unexpectedly Achieving}


Brown et al (1997: 1) note the importance of 'ensuring that student learning matches course objectives' as a current concern within higher education. Certainly there is much contemporary focus on mapping curricula to pre-set objectives in order to assess whether, or not, learning outcomes have been achieved and whether, of course, learners consequently consider their experiences worthwhile. However, in its emphasis on the pre-planned, such an approach neglects the realm of the unexpected and its relationship to the pleasures of achievement. The following examples illustrate these aspects. Thus, trying new things might be hard work but the sense of achievement arising from having to work hard in a situation one never expected to find oneself can still be enjoyable:

It was something that I wanted to do or would have liked to have done ... I never thought I would get round to doing it. I sort of, it was a complete learning curve. Me. I hadn't done anything like it before. It was a case of yes, I wanted to do it. I never thought I would get round to it and that opportunity was there and I did really enjoy it. It was hard work. I lost quite a lot of weight. It was so physical and being small as well.

Similarly, rising to specific challenges that appeared unachievable leaves a sense of pleasure as one performs on a daunting occasion:

What it also gives you, what it gave me, was ... built confidence. I mean to get up in one of these massive auditoriums and to speak to 300 people. So, and again, it was good because it was all based on, everybody used to do, you had to do a presentation

Finally, there is the pleasure at being marked out as special as not only do the comments 'it was good .... it was really good' indicate but so does the laughter:

Whoever was doing the lecture would pick four from the whole of the group to actually present their piece. So I was picked twice. After the second time I thought I am not doing it to that standard again [laughter]. I had enough of that. It was good. ... It was 
really good.

\section{Concluding Discussion}

This paper has argued that pleasure is a relatively neglected concept in accounts of learning. It has, therefore, sought to contribute to developing understandings by outlining two frames of analysis through which we can further map the contours, variables and shapes of pleasure and their relevance to learning as a multifaceted experience. The paper began with a Foucauldian analysis through which pleasure is analysed as an aspect of the panoply of relations of domination. Here, the paper has explored the production of the admirable life of the learner in a learning organisation through a focus on quantification and role. The analysis concluded by noting how the language of 'pushing for' illustrates the success of processes of subjectification as the learner both takes up, and is taken up by, learning discourses.

Notwithstanding Foucault's hopes that his analysis will offer us a way of conceptualising resistance in more liberatory ways, we are still left with the problem that pleasure appears to remain a proxy or a cipher for the operations of disciplinary power. Pleasure becomes part of the disciplining processes that we are subjects of and subjected to. Accordingly, pleasure as a sensation and as an experience is not merely left in the background doing its work, as it were, for power. It is erased.

Through a phenomenological focus, the aim was to celebrate pleasure for pleasure's sake. This was to provide an antidote to what can often be understood as the inevitable, and sometimes alienable, pessimism of critical analysis. Here, a phenomenological analysis demonstrates how pleasure is an important lived moment in the experiences of those who engage in learning and educational activities. In this respect, the paper has begun to map some of the ways in which pleasure is produced. This is evidenced not only through comments such as having a 'good time' and 'fun' but also through the bodily dispositions of research respondents as they smiled, laughed 
or appeared relaxed as their words simultaneously reinvoked the embodied sensations of pleasure. Indeed, when one compares the language used in the illustrative quotations from research respondents in each section of the paper there is a marked contrast. There is, for example, quite an absence of the word 'fun' from the accounts in the Foucauldian section. No doubt further work can be conducted that more fully explores the linkage between a variety of forms of learning and their meanings for the production of pleasure.

It is clear, therefore, that these two analytic frames do different work in terms of the production of knowledge. In this regard, Danahier et al (2000) note how Foucault's work can be understood as a reaction against phenomenology - a system of thought with which he would have been very familiar. They comment that 'Foucault was far more interested in, and receptive to, work which, instead of trying to understand the 'one and only' truth of things, tried to 'historicise' the different kinds of truth, knowledge, rationality and reason that had developed in cultures' ( $p$ 6). Certainly, in its descriptive emphasis, the phenomenological account presented here limits the extent to which we can explore the ethics and politics of pleasure. For example, the phenomenological account has suggested that the situational experiences of pleasure discussed cross gender, and other, forms of social division. When discussing time, learning environment and unexpected achievement as abstract categories, I believe that this is the case. However, more fully contextualised analyses of, say, the gendered relations of pleasure may well illustrate how, for example, achieving as a woman in a male environment can be experienced, in itself, as pleasurable. Similarly, finding pleasure in particular topics of learning, such as computer technology, or finding certain pedagogic approaches more pleasurable than others may be attributed to gender orientations.

Notwithstanding, pleasure as a category is problematic for those of us who are interested in developing informed, political accounts of social relations. Such a point is raised by Gard and Meyenn (2000) in their discussion of the pleasures experienced by boys when engaged in contact sports. They note how pleasure has been a 'largely unspoken and dangerous territory, both for the boys and for us' ( $p$ 19). This is both because there is an insufficiency of languages of 
pleasure to enable individuals to adequately express such pleasures and also because 'intimate physical contact between Western males has long represented fraught cultural territory' ( $p$ 28). In consequence, Gard and Meyenn note how, in a climate of concern around pedophilia, asking questions about pleasure and intimate same sex sporting contact presented a significant ethical dilemma. Are they, for example, providing evidence for further control and limitation of such activities or even providing the grist for a moral panic? Swan (2005) also details the dilemmas in accounting for pleasure in her sense of mastery (sic) in performing masculinity as a teacher in the management classroom. On the one hand she notes how it appears unacceptable to simply accept pleasure as a thing itself requiring no explanation except for viewing it as an aspect of lived experience. Rather she experiences a sense that her pleasure in performing masculinity has to be intellectually explained in terms of resistance, politics or better pedagogical outcomes. On the other hand, Swan also reflects on the dangers of overlooking the potential of sexual and other forms of abuse when foregrounding erotics, teacher pleasure and sensuality in pedagogical discussions.

It may be a mistake, however, to assume that the two analytic frames presented here are inevitably oppositional or incompatible or more generally that one has to choose between the critical account and the descriptive. Or that one has to focus on pleasure or ignore it altogether. Pleasure as a category is politically problematic but, as Swan has noted, we cannot deny its existence. Thus, Barthes (1975) sought to develop a critical vocabulary that would enable us to describe the varied pleasures and blisses of the text. Other research, cited here, has indicated how pleasure may be erotic or nomadic. To date, however, we have limited resources for describing different forms of pleasure and limited research that explores how different forms of learning produce different pleasures and what kinds of pleasure are most strongly associated with the operations of power. This surely suggests that pleasure requires more interrogation rather than less. Indeed, when we return to the two frames of analysis that have been the focus of this paper, we might see them as reflexive of one another. Pleasure can be a fleeting experience, a lived moment and no more. Pleasure may be part of an armament of experiences as the 
momentary good feelings that arise are more fully embedded and embodied in the configuration of a sense of self. In this way, the descriptive account of phenomenology provides the texture of daily experience. Foucault's ethical analysis of the admirable life provides one form of critical understanding of pleasure's binding power. Certainly, to echo McWilliam (1996), much fruitful work remains to be done in the analysis of pleasure and learning.

\section{References}

Barthes, R (1975) The Pleasure of the Text (Toronto, Doubleday)

Blaxter, L, Hughes, C and Tight, M (1997) Education, work and adult life: how adults relate their learning to their work, family and social lives, in P Sutherland (Ed) Adult Learning: A Reader (London, Kogan Page)

Brookfield, S (1986) Understanding and Facilitating Adult Learning (Milton Keynes, Open University Press)

Brown, G with Bull, J and Pendlebury, M (1997) Assessing Student Learning in Higher Education (London, Routledge)

Crotty, M (1998) The Foundations of Social Research (London, Sage)

Danahier, G, Schirato, T and Webb, J (2000) Understanding Foucault (London, Sage)

Davies, B, Dormer, S, Gannon, S, Laws, C, Taguchi, H, McCann, H and Rocco, S, (2001)

Becoming Schoolgirls: The Ambivalent Project of Subjectification, Gender and Education, 13, 2, pp 167-182

Edwards, R and Usher, R (2000) Globalisation and Pedagogy: Space, Place and Identity (London, Routledge/Falmer) 
Edwards, R and Usher, R (2001) Lifelong Learning: A Postmodern Condition of Education? Adult

Education Quarterly, 51, 4, 273-287

Foucault, M (1985) The Use of Pleasure: The History of Sexuality, Vol II (Harmondsworth, Penguin)

Gard, M and Meyenn, R (2000) Boys, Bodies, Pleasure and Pain: Interrogating Contact Sports in Schools, Sport, Education and Society, 5, 1, 19-34

Garrick, J (1998) Informal Learning in the Workplace: Unmasking Human Resource Development (London, Routledge)

Groden, M and Kreiswirth, M (1997) The Johns Hopkins Guide to Literary Theory and Criticism, Philadelphia, Johns Hopkins University Press

(http://www.press.jhu.edu/books/hopkins_guide_to_literary-theory/roaldn_barthes.html, accessed 23.02.05)

Groenewald, T (2004) A Phenomenological Research Design Illustrated, International Journal of Qualitative Methods, 3, 1, 1-26

(http://www.ualberta.ca/ iiqm/backissues/3 pdf/groenewald.pdf, accessed 19/03/05)

Hughes, C (2002) Scaling the theoretical wall of the poststructural-modern impasse through the case of the woman returner as 'exile' and 'nomad', Gender and Education, 14, 4, 411-424

Huserl, E (1931) Ideas: General Introduction to Pure Phenomenology (Evanston, North Western University Press)

Merleau-Ponty, M (1962) Phenomenology of Perception (London, Routledge and Kegan Paul) McWilliam, E (1996) Touchy Subjects: A Risky Inquiry into Pedagogical Pleasure, British Educational Research Journal, 22, 3, 305-317 
McWilliam, E and Jones, A (1996) Eros and Pedagogical Bodies: the state of (non)affairs in E McWilliam and P Taylor (Eds) Pedagogy, Technology and the Body (New York, Peter Lang)

McWilliam, E (1999) Pedagogical Pleasures (New York, Peter Lang)

Moi, T (1999) What is Woman? Oxford, Oxford University Press

Parry, O and Mauthner, N (2004) Whose Data Are They Anyway? Practical, Legal and Ethical Issues in Archiving Qualitative Research Data, Sociology, 38, 1, 139-152

Promozic, D (2001) On Merleau-Ponty (Belmont, CA, Wadsworth)

Swan, E (2005) Bodies, Rhinestones and Pleasures: Women teaching managers, Management Learning, 36, 3

Tight, M (1998) Lifelong Learning: Opportunity or Compulsion? British Journal of Educational Studies, 46, 3, 251-263

Velarde-Mayol, V (2000) On Husserl (Belmont, CA, Wadsworth)

Willis, P (2001) The 'Things Themselves' in Phenomenology, Indo-Pacific Journal of

Phenomenology, 1, 1, 1-14 (www.ipjp.org, accessed 15/03/05) 